\title{
Sistem Pengendalian Intern Dalam Pemberian Kredit Usaha Masyarakat di Badan Usaha Milik Desa (BUMDES) Tirta Rahayu Desa Yeh Sumbul, Kecamatan Mendoyo, Kabupaten Jembrana
}

\author{
Andi Yahya ${ }^{1 *}$, Kadek Rai Suwena ${ }^{2}$ \\ ${ }^{1,2}$ Program Studi Pendidikan Ekonomi, Universitas Pendidikan Ganesha, Singaraja, Indonesia \\ *andi83817@gmail.com ${ }^{\text {* }}$
}

\section{Abstrak}

Tujuan dari penelitian ini adalah untuk mengetahui sistsem pengendalian intern dalam pemberian kredit usaha masyarakat di Badan Usaha Milik Desa (BUMDES) Tirta Rahayu dan untuk mengetahui masalah yang dihadapi oleh Badan Usaha Milik Desa (BUMDES) Tirta Rahayu dalam melaksanakan sistem pengendalian intern pemberian kredit. Jenis penelitian ini adalah deskriptif kualitatif. Lokasi penelitian pada penelitian ini adalah pada Badan Usaha Milik Desa (BUMDES) Desa Yeh Sumbul, kecamatan Mendoyo, Kabupaten Jembrana. Subjek dalam penelitian ini adalah Kepala BUMDES Tirta Rahayu Desa Yeh Sumbul, Sekretaris BUMDES Tirta Rahayu Desa Yeh Sumbul dan Pengawas BUMDES Tirta Rahayu Desa Yeh Sumbul. Objek dari penelitian ini adalah sistem pengendalian intern dalam pemberian kredit usaha masyarakat di BUMDES Desa Yeh Sumbul. Metode pengumpulan data menggunakan metode observasi serta wawancara, metode observasi digunakan untuk pengamatan langsung ke lokasi pada Badan Usaha Milik Desa Tirta Rahayu Desa Yeh Sumbul. Sistem pengendalian intern di BUMDES Tirta Rahayu Desa Yeh Sumbul secara garis besar sudah dilaksanakan sesuai dengan kaidah yang berlaku. Masalah yang dihadapi BUMDES Tirta Rahayu dalam Melaksanakan Sistem Pengendalian Intern Pemberian Kredit adalah SDM yang kurang memadai, SDM yang dimiliki BUMDES Tirta Rahayu dirasa masih kurang karena jumlah karyawan terlalu sedikit dan kualitas pendidikan yang rendah selain itu kedisiplinan pengurus dalam menjalankan tugas dirasa kurang baik, sehingga dalam melaksanakan tugas kerap membutuhkan waktu yang lama.

Kata Kunci : Sistem Pengendalian Intern; Kredit Usaha; BUMDES

\section{Abstract}

The purpose of this study was to determine the internal control system in providing community business credit at Tirta Rahayu Village-Owned Enterprises (BUMDES) and to find out the problems faced by Tirta Rahayu Village-Owned Enterprises (BUMDES) in implementing the credit-giving internal control system. This type of research is descriptive qualitative. The research location in this study is the Village-Owned Enterprises (BUMDES) Yeh Sumbul Village, Mendoyo District, Jembrana Regency. The subjects in this study were the Head of BUMDES Tirta Rahayu Yeh Sumbul Village, the BUMDES Secretary Tirta Rahayu Yeh Sumbul Village and the BUMDES Supervisor Tirta Rahayu Yeh Sumbul Village. The object of this research is the internal control system in providing community business credit in BUMDES Yeh Sumbul Village. The data collection method used the observation and interview methods, the observation method was used for direct observation to the location of the Tirta Rahayu Village Owned Enterprise, Yeh Sumbul Village. In general, the internal control system at BUMDES Tirta Rahayu Yeh Sumbul Village has been implemented in accordance with applicable rules. The problems faced by BUMDES Tirta Rahayu in Implementing the Internal Control System for Providing Credit are inadequate human resources, HR owned by BUMDES Tirta Rahayu is still lacking because the number of employees is too few and the quality of education is low besides that the management's discipline in carrying out their duties is deemed not good, so that in carrying out the task often takes a long time.

Keywords: Internal Control System; Business Credit; BUMDES

$\begin{array}{ll}\text { History: } & \text { Publisher: Undiksha Press } \\ \text { Received: August } 2021 & \text { Licensed: This work is licensed under } \\ \text { Revised: Oktober } 2021 & \text { a Creative Commons Attribution 3.0 License } \\ \text { Accepted: November } 2021 & \end{array}$




\section{Pendahuluan}

Kondisi perekonomian masyarakat desa di Indonesia terus mengalami banyak perubahan ekonomi hal tersebut dipengaruhi oleh faktor internal desa sendiri, yaitu dengan berlakunya undang-undang desa. Berlakunya undang-undang desa dapat meningkatkan pemberdayaan masyarakat yang disebabkan bergeraknya sektor riil di desa yang dibantu pengelolaan dananya oleh Badan Usaha Milik Desa (BUMDES). BUMDES adalah sebuah lembaga usaha desa yang dikelola oleh pemerintah desa juga masyarakat desa tersebut dengan tujuan untuk memperkuat perekonomian desa dan dibentuk berdasarkan kebutuhan serta potensi yang ada di desa tersebut (Amalia, 2014)

Eksistensi Badan Usaha Milik Desa semakin meningkat dari waktu ke waktu. Hal ini karena masyarakat banyak yang memanfaatkan keberadaan BUMDES untuk meminjam dana. Jumlah BUMDES meningkat signifikan dimana pada tahun 2014 hanya terdapat 1.022 unit unit BUMDES, pada tahun 2015 naik 10 kali lipatnya menjadi 12.115 unit (kppod.org, dikutip tanggal 19 Maret 2021). Pada tahun 2016 18.446 Unit, 2017 jumlah BUMDES di Indonesia juga mengalami peningkatan sebanyak 4.000 unit menjadi 14.686 unit dan Tahun 2019 menjadi 50.199 unit (lokadata.id, dikutip tanggal 19 Maret Pebruari 2021). Menurut Sekjen Kemendes dan PDTT Anwar Sanusi, hingga 2019 jumlah BUMDES telah mencapai 50.199 unit dari 74.910 desa di Indonesia (46,72\% desa di Indonesia telah memiliki BUMDES). Jumlah ini tujuh kali lipat dari target yang tercantum dalam Rencana Pembangunan Jangka Menengah Nasional (RPJMN) 2014-2019 yaitu berdiri 5.000 unit BUMDES (Beritasatu.com, dikutip tanggal 19 Maret 2021). Namun sangat disayangkan pertumbuhan fantastis BUMDES ini belum disertai dengan kualitas yang memadai. Sekjen Kemendes dan PDTT Anwar Sanusi menyatakan bahwa dari 22.000 unit BUMDES pada tahun 2019, rata-rata masih dalam kondisi berkembang. Sedangkan untuk BUMDES yang masuk dalam kategori maju secara nasional hanya sekitar 50 unit saja $(0,23 \%)$ (detiknews, dikutip tanggal 19 Maret 2021). Disamping itu, dari data 50.199 unit BUMDES sampai September 2019, yang aktif hanya 2.146 unit (11,63\%) (Jatimsindonews.com; bumdes.id, dikutip tanggal 19 Maret 2021). Sekjen Forum Badan Usaha Milik Desa (BUMDES) Indonesia Rudy Suryanto juga menyebut dari 27.067 BUMDES hanya sekitar $10 \%$ yang usahanya jalan, sedangkan sisanya tidak jalan atau ada yang jalan namun tidak dapat memberikan keuntungan (harian jojga, dikutip tanggal 19 Maret 2021)

Fenomena serupa juga terjadi di Kabupaten Jembrana, Provinsi Bali, berdasarkan data yang diperoleh dari Dinas Pemberdayaan Masyarakat dan Desa untuk Tahun 2020 kondisi existing BUMDES di Kabupaten Jembrana.

Fenomena 37 Persen BUMDES bermasalah di Kabupaten Jembrana, sejalan dengan kenaikan alokasi Dana desa ke BUMDES dengan berbagai kebijakan yang memayungi BUMDES, Hal ini menunjukan bahwa pengelolaan BUMDES di Indonesia pada umumnya dan Kabupaten Jembrana pada khususnya menunjukkan bahwa pengelolaan BUMDES sampai saat ini masih belum optimal. Di sektor bisnis sendiri, sudah banyak perusahaan yang hancur sebagai akibat dari tidak optimalnya tata kelola (Warsono, dkk, 2009). Berbagai permasalahan yang dihadapi oleh BUMDES di Kabupaten Jembrana salah satunya adalah kredit macet. Kredit macet menjadi permasalahan yang sering terjadi di setiap lembaga keuangan. Hampir semua lembaga keuangan pasti mengalami masalah ini. Menurut Riva'i (2004) kredit macet merupakan kesulitan nasabah di dalam penyelesaian kewajibankewajibannya terhadap bank atau lembaga keuangan non bank, baik dalam bentuk pembayaran kembali pokoknya, pembayaran bunga, maupun pembayaran ongkos-ongkos yang menjadi beban bagi nasabah yang bersangkutan. Kredit macet dapat menyebabkan kerugian pada lembaga keuangan karena dana yang disalurkan tidak dapat kembali dan juga lembaga keuangan tersebut gagal untuk memperoleh bunga yang merupakan salah satu 
pendapatan bagi BUMDES. Faktor intern dan faktor ekstern merupakan penyebab dari kredit bermasalah. Kurang tepatnya analisis kredit, kolusi yang terjadi pada pejabat lembaga keuangan, kurangnya pengetahuan, lemahnya pembinaan dan pengawasan, merupakan faktor intern yang menyebabkan kredit bermasalah. Untuk faktor ekstern biasanya berasal dari peminjam yang tidak mengembalikan kredit, penggunaan pinjaman yang tidak sesuai dengan tujuan dan bencana alam.

Pemberian kredit tersebut harus dilakukan secara hati-hati dengan prosedur kredit yang tepat sehingga dana yang disalurkan tepat sasaran dan bisa kembali sesuai dengan perjanjian yang ditentukan mengingat dana tersebut adalah milik masyarakat desa yang penarikannya bisa dilakukan sewaktu-waktu. Selain itu dana yang disalurkan kepada masyarakat juga merupakan sumber kekayaan dari BUMDES yang diperoleh dari bunga pinjaman yang diberikan. Sebagai salah satu lembaga usaha desa, BUMDES Tirta Rahayu harus melayani masyarakatnya dalam hal pendanaan misalnya ada masyarakat yang kesulitan dalam modal untuk mengembangkan usahanya, pendanaan untuk upacara agama dan lain-lain, dari informasi dan data yang penulis dapatkan masalah yang paling sering dialami dalam pemberian kredit masyarakat adalah keterlambatan nasabah dalam pengembalian dana pinjaman. Pada BUMDES Tirta Rahayu di Desa Yeh Sumbul, dari tahun 2017-2019 dapat dikatakan mengalami peningkatan jumlah kredit macet dari tahun ke tahun. Meski dari pihak BUMDES selalu berupaya untuk memperbaiki sistem pemberian kredit dan mencari proses penyelesaian yang tepat agar masalah kredit bermasalah ini dapat teratasi dengan baik, namun upaya tersebut belum membuahkan hasil yang optimal.

Data kredit macet BUMDES Tirta Rahayu Desa Yeh Sumbul, Kecamatan Mendoyo, Kabupaten Jembrana pada tahun 2017 sebanyak 9 debitur dengan total kredit macet sebesar Rp. 12.300.000,00. Pada tahun 2018 meningkat menjadi 28 debitur dengan total kredit macet sebesar Rp. 28.725.000,00. Dan tahun 2019 terus mengalami peningkatan hingga mencapai 31 debitur dengan total kredit macet sebesar Rp. 45.596.000,00. Permasalahan ini jika tidak segera ditanggulangi akan dapat mengakibatkan resiko kerugian bagi BUMDES itu sendiri dan jika tidak segera ditanggulangi akan mengakibatkan banyak masalah mengingat sumber dana yang dimiliki oleh BUMDES juga berasal dari tabungan masyarakat.

Dari latar belakang diatas, peneliti memfokuskan untuk mengetahui sistem pengendalian internal dalam pemberian kredit usaha masyarakat di Badan Usaha Milik Desa (BUMDES), sehingga dapat mengetahui apakah sistem pengendalian intern pemberian kredit di Badan Usaha Milik Desa (BUMDES) sudah berjalan dengan baik atau belum optimal. Oleh karena itu, peneliti mengangkat judul "Sistem Pengendalian Intern Dalam Pemberian Kredit Usaha Masyarakat di Badan Usaha Milik Desa (BUMDES) Tirta Rahayu Desa Yeh Sumbul, Kecamatan Mendoyo, Kabupaten Jembrana".

Badan Usaha Milik Desa (BUMDES) adalah salah satu lembaga usaha desa yang yang dikelola oleh pemerintah dan masyarakat desa yang dibentuk berdasarkan kebutuhan dan potensi desa. BUMDes selain sebagai lembaga sosial atau lembaga yang berpihak kepada kepentingan masyarakat, BUMDes juga merupakan lembaga komersil atau lembaga yang bertujuan untuk mencari keuntungan yang mana menurut Undang-Undang Nomor 32 Tahun 2004 tentang Pemerintahan Daerah bahwa tujuan pendirian BUMDes antara lain adalah untuk meningkatkan Pendapatan Asli Desa (PADesa). BUMDes Tirta Rahayu Desa Yeh Sumbul merupakan salah satu BUMDes yang membuka unit usaha simpan pinjam. Unit usaha simpan pinjam ini dibentuk dengan tujuan untuk membantu masyarakat Desa Yeh Sumbul dalam kegiatan ekonomi baik yang bersifat konsumtif maupun produktif. Dengan adanya unit usaha ini dapat terlihat jelas bahwa salah satu kegiatan operasional BUMDES adalah melakukan pemberian kredit.

Raymond P. Kent (dalam Ismail, 2014:220) menyatakan bahwa kredit adalah suatu hak untuk menerima pinjaman dana dan kewajiban untuk mangembalikan pinjaman pada saat 
jatuh tempo. Menurut Hasibuan (2001) kredit dapat diartikan sebagai semua pinjaman yang harus dikembalikan beserta bunga oleh kreditur sesuai perjanjian. Rivai (2004) menyatakan kredit adalah penyerahan barang modal atas asas kepercayaan kepada kreditur dengan perjanjian pengembalian yang telah disetujui. Sedangkan menurut Sastradipoera (2004) kredit dapat diartikan sebagai penyediaan uang dengan berbagai kesepakatan yang dibutuhkan dimana peminjam berkewajiban mengembalikan uang yang dipinjam berserta bunga yang disepakati

Kredit macet dapat diartikan sebagai pinjaman yang mengalami kesulitan pelunasan akibat adanya faktor kesengajaan dan atau karena faktor eksternal diluar kemampuan kendali debitur (Dahlan, 2001:174). Sedangkan menurut Veithzal Rivai (2008:477) kredit macet merupakan kesulitan nasabah di dalam penyelesaian kewajiban-kewajibannya terhadap lembaga, baik dalam bentuk pembayaran kembali pokoknya, pembayaran bunga, maupun pembayaran ongkos-ongkos yang menjadi beban nasabah debitur yang bersangkutan. Kredit macet adalah suatu keadaan dimana nasabah sudah tidak sanggup membayar sebagian atau seluruh kewajibannya kepada bank atau lembaga non bank seperti yang telah diperjanjikan (Mudrajat Kuncoro dan Suhardjono, 2002:462).

Pengendalian Intern merupakan bagian dari manajemen resiko yang harus dilaksanakan oleh setiap lembaga untuk mencapai tujuan lembaga. Demikian perlunya pengendalian internal dalam sebuah lembaga sehingga hal ini harus dilaksanakan secara konsisten untuk menjamin kesinambungan dan kepercayaan pihak donor maupun masyarakat.

\section{Metode}

Jenis penelitian deskriptif kualitatif adalah yang digunakan dalam penelitian ini. Penelitian deskriptif kualitatif yaitu penelian yang menggambarkan keadaan atau status fenomena yang terjadi pada suatu temopat (Arikunto,2001). Lokasi penelitian pada penelitian ini adalah pada Badan Usaha Milik Desa (BUMDES) Desa Yeh Sumbul, kecamatan Mendoyo, Kabupaten Jembrana.

Subjek dalam penelitian ini adalah Kepala BUMDES Tirta Rahayu Desa Yeh Sumbul, Sekretaris BUMDES Tirta Rahayu Desa Yeh Sumbul dan Pengawas BUMDES Tirta Rahayu Desa Yeh Sumbul. Objek dari penelitian ini adalah sistem pengendalian intern dalam pemberian kredit usaha masyarakat di BUMDES Desa Yeh Sumbul. Jenis data yang digunakan dalam penelitian ini adalah data kualitatif yang dengan menggunakan sumber data primer dan data skunder.

Metode pengumpulan data menggunakan metode observasi serta wawancara, metode observasi digunakan untuk pengamatan langsung ke lokasi pada Badan Usaha Milik Desa Tirta Rahayu Desa Yeh Sumbul, dengan tujuan penulis dapat mengetahui dan mendapatkan data yang diperlukan dari penelitian ini. Adapun observasi yang dilakukan oleh peneliti yaitu observasi berkaitan dengan sistem pengendalian intern pemberian kredit dan masalah yang terdapat di Badan Usaha Milik Desa Tirta Rahayu Desa Yeh Sumbul. Sedangkan metode wawancara digunakan untuk melakukan tanya jawab langsung kepada informan dari BUMDES Tirta Rahayu untuk mendapatkan informasi terkait dengan data yang diperlukan dari penelitian. Wawancara yang dilakukan bertujuan untuk menjawab rumusan masalah dari penelitian ini yaitu mengenai sistem pengendalian intern dalam pemberian kredit di Badan Usaha Milik Desa kepada informan antara lain, pimpinan Badan Usaha Milik Desa Tirta Rahayu, Sekretaris, dan Pengawas BUMDES Tirta Rahayu Desa Yeh Sumbul. Peneliti sendiri akan melakukan penelitian dengan menggunakan alat wawancara seperti buku catatan, tape recorder dan camera. Selain itu juga peneliti menggunakan pedoman dan daftar pertanyaan (terlampir) agar dalam melakukan penelitian, informasi yang di cari benar adanya dan tidak menyimpang dari apa yang diharapkan. Pedoman yang digunakan adalah pedoman 
tentang sistem pengendalian intern menurut teori Mulyadi (2010), serta yang terakhir metode dokumentasi digunakan untuk mengumpulkan dokumen yang dibutuhkan pada saat penelitian.

Analisi data yang digunakan dalam penilitian ini menggunakan analisi interaktif yaitu dengan melakukan pengumpulan data terlebih dahulu serta reduksi data dan disusul dengan penyajian data yang valid.

\section{Hasil dan Pembahasan}

Sistem pengendalian intern dalam pemberian kredit di Badan Usaha Milik Desa (BUMDES) Tirta Rahayu berupaya untuk menjaga kekayaan BUMDES meskipun dana yang disalurkan kepada masyarakat dalam bentuk kredit. BUMDES Tirta Rahayu terus berusaha agar dana yang disalurkan tersebut dapat kembali dan BUMDES mendapat bunga untuk meningkatkan profitabilitas. Adapun sistem pengendalian intern yang dilakukan oleh BUMDES Tirta Rahayu yaitu: (1) Struktur Organisasi yang memisahkan Tanggung Jawab Fungsional Secara TegasBUMDES Tirta Rahayu Desa Yeh Sumbul melaksanakan kegiatan operasionalnya sesuai dengan pembagian tugas berdasarkan struktur organisasinya. Sehingga dalam pelaksanaan tugas setiap karyawan sudah mendapatkan uraian tugas yang jelas sesuai dengan bidangnya.

"Pembagian tugas di BUMDES Tirta Rahayu sudah diatur dalam standar pedoman pelaksanaan kerja, kita bekerja sesuai dengan tugas masing-masing, sesuai dengan pembagian tugas yang telah ditetapkan. Namun jika ada pekerjaan yang belum terselesaikan kita kerjakan bersama-sama dengan cara membagi tugasnya tetapi menjadi tanggung jawab bersama" (Muhlis, 2021)

"Pembagain tugas di BUMDES Tirta Rahayu tentunya disesuaikan dengan unit usaha yang ada, kalau unit simpan pinjam ya mengurus simpan pinjam, yang unit perdangan ya merungus perdagangan, dan unit futsal ya mengurus penyewaan lapangan tersebut. Kecuali jika ada karyawan yang tidak bekerja barulah kita saling membantu agar semua unit tetep berjalan. (Diah Marlia, 2021).

Berdasarkan hasil wawancara diatas dapat diketahui bahwa pembagian tugas di BUMDES Tirta Rahayu sudah sesuai dengan peraturan yang berlaku, baik ketua, sekretaris, maupun bendahara telah melakukan pekerjaannya sesuai dengan tugasnya masing-masing termasuk dalam hal pemberian kredit. Meskipun tugas yang dikerjakan oleh masing-masing petugas tetapi tetap menjadi tanggung jawab dari setiap bidang. (2) Sistem Wewenang dan Prosedur Pencatatan yang Memberikan Perlindungan yang Cukup Terhadap Kekayaan. Sistem wewenang dan prosedur pencatatan yang memberikan perlindungan yang cukup terhadap kekayaan diterapkan oleh BUMDES Tirta Rahayu Desa Yeh Sumbul melalui transaksi yang dilakukan harus disetujui dan diotorisasi oleh atasannya.

"Iya harus ada, setiap transaksi harus ada tanda tangan dari bapak perbekel dan pengawas, jadi setiap transaksi akan diperiksa dlu oleh atasannya baik bapak perbekel maupun pengawas" (Muhlis, 2021).

"Harus ada, karena setiap transaksi harus diketahui oleh atasan dan harus ditandatangani oleh bapak perkel Desa Yeh Sumbul dan Pengawas BUMDES" (Diah Marlia, 2021).

Informasi yang peneliti dapat dari kepala BUMDES dan sekretaris adalah setiap trasaksi yang dilakukan di BUMDES Tirta Rahayu Desa Yeh Sumbul harus diketahui oleh 
atasannya yaitu Perbekel Desa Yeh Sumbul dan Pengawas BUMDES Tirta Rahayu. Transaksi tersebut akan diperiksa kebenarannya oleh atasannya untuk meminimalisir terjadinya kesalahan sedini mungkin, untuk itu setiap transaksi harus ada dua tanda tangan yaitu tanda tangan dari Perbekel Desa Yeh Sumbul dan Pengawas BUMDES Tirta Rahayu. (3) Praktik yang Sehat dalam Melaksanakan Tugas dan Fungsi Setiap Unit Organisasi Praktik yang sehat dalam melaksanakan tugas dan fungsi setiap unit organisasi di BUMDES Tirta Rahayu Desa Yeh Sumbul dilakukan dengan cara penggunaan formulir yang berbeda untuk setiap transaksi serta dipertanggung jawabkan oleh petugas yang menangani transaksi tersebut.

"Penggunaan formulirnya berbeda-beda dik, sesuai dengan transaksinya". "Iya yang bertanggung jawab adalah unit simpan pinjam” (Muhlis, 2021).

"Iya, karena di unit simpan pinjam tidak cuma ada satu transaksi, tentu yang bertanggung jawab adalah yang menangani transaksi tersebut yaitu unit simpan pinjam" (Diah Marlia, 2021).

Selain itu pemeriksaan mendadak juga dilakukan oleh atasan yaitu dari pengawas, PMD Kabupaten, dan pendamping.

"Iya, kadang-kadang ada pemeriksaan mendadak dari pengawas BUMDES Tirta Rahayu, dan kadang-kadang dari dinas PMD Kabupaten dan juga dari pendamping". "Tidak ada sanksi bagi karyawan yang kinerjanya kurang bagus paling hanya diberikan teguran saja" (Muhlis, 2021).

"Pernah, pemeriksaan terkadang dilakukan oleh pengawas maupun Dinas PMD tatkala ada hal-hal yang terjadi yang membuat kesulitan karyawan” (Diah Marlia, 2021).

Pemeriksaan mendadak dilakukan oleh pengawas BUMDES Tirta Rahayu, PMD Kabupaten, dan pendamping. Untuk memantau kinerja karyawan, namun jika ada karyawan yang kinerjanya kurang bagus atasan hanya memeberikan sebuah teguran tanpa memberikan sanksi bagi karyawan tersebut. Setiap transaksi di BUMDES Tirta Rahayu dilaksanakan oleh petugas yang bersangkutan yaitu unit simpan pinjam dan dipertanggung jawabkan bersama anggotanya sehingga kesalahan yang mungkin akan terjadi dapat diketahui lebih awal sesuai dengan hasil wawancara kepala BUMDES Tirta Rahayu dan bagian kredit.

"Setiap transaksi dilakukan oleh unit simpan pinjam jadi mereka akan melakukan tugasnya bersama-sama dengan cara membagi tugas yang tentu akan menjadi tanggung jawab bersama" (Muhlis, 2021).

"Tugas ini tidak mutlak dilakukan oleh satu orang saja, kita bekerja sama dalam menyelesaikan tugas tersebut" (Diah Marlia, 2021).

Tidak ada perputaran jabatan di BUMDES Tirta Rahayu, karena pengurus BUMDES dilantik serta diambil sumpah oleh perbekel dan masa baktinya telah diatur dalam Anggaran Rumah Tangga (ART). Berdasarkan Keputusan Perbekel Nomor 27 tahun 2017 BAB VIII tentang Pengurusan dan Pengelolaan Badan Usaha Milik Desa (BUMDES) pasal 11 mengenai masa bakti kepengurusan BUMDES, struktur kepengurusan akan diganti setelah 2 
periode. Seperti yang dikatakan oleh bapak Muhlis ketua BUMDES Tirta Rahayu dan Diah Marlia sebagai sekretaris sekaligus kepala bagian kredit.

"Ada perputaran jabatan di BUMDES ini dik, karena masa jabatan kepengurusan BUMDES sudah diatur Berdasarkan Keputusan Perbekel Nomor 27 tahun 2017 BAB VIII tentang Pengurusan dan Pengelolaan Badan Usaha Milik Desa (BUMDES) pasal 11 mengenai masa bakti kepengurusan BUMDES. Jadi masa jabatannya itu akan diganti setelah 2 periode" (Muhlis, 2021).

"Tentu ada, hanya saja perputaran jabatan itu terjadi setelah masa bakti kepengurusan sudah berakhir dan masa jabatan itu akan diganti setelah 2 periode" (Diah Marlia, 2021).

Tidak ada kebijakan pemberian cuti untuk karyawan di BUMDES Tirta Rahayu. Namun jika ada karyawan yang tidak bisa hadir untuk berkerja karena memiliki kepentingan seperti ada upacara agama, sakit, ataupun kendala yang lain karyawan tersebut tidak akan diberikan sanksi dan tetap akan menerima gaji atau upah yang sama. Karena di BUMDES ini berkerja menggunakan sistem kekeluargaan dan jika ada karyawan yang tidak bisa hadir berkerja maka pekerjaan karyawan yang bersangkutan akan dikerjakan oleh karyawan lain agar pekerjaan tersebut tidak tertunda.

"Tidak ada cuti, kalaupun ada yang tidak bisa bekerja maka tugasnya akan diambil alih oleh karyawan yang lain karna di BUMDES ini berkerja menggunakan sistem kekeluargaan. Tidak ada sanksi khusus bagi karyawan yang tidak bekerja dan ia tetap akan menerima gaji yang sama" (Muhlis, 2021).

"Sampai saat ini belum ada cuti, namun jika ada karyawan yang tidak bekerja maka tugasnya akan digantikan oleh karyawan yang lain, karena dalam BUMDES ini kita bekerjasama kalau ada tugas yang belum terselesaikan” (Diah Marlia, 2021).

Pencocokan fisik kekayaan dengan catatannya juga dilaksanakan rutin setiap bulannya dengan cara manual, dimana setiap bulannya sudah dicocokkan dengan dihitung menggunakan neraca yang dilakukan bersama Pengawas BUMDES. Pengurus BUMDES juga memberikan laporan perkembangan unit-unit usaha termasuk unit simpan pinjam kepada masyarakat desa melalui musyawarah desa sekurang-kurangnya 2 (dua) kali dalam 1 (satu) tahun.

"Iya, pencocokan fisik kekayaan BUMDES Tirta Rahayu dengan catatannya dilakukan setiap bulan secara manual dengan dihitung lewat neraca dimana dalam kegiatan tersebut kita juga melibatkan bapak perbekel, pengawas BUMDES dan BPD. Kemudian setelah kita melakukan pencocokan kita juga memberikan laporan perkembangan unit-unit usaha termasuk unit simpan pinjam kepada masyarakat desa yang dilakukan sekurang-kurangnya 2 (dua) kali dalam 1 (satu) tahun" (Muhlis, 2021).

"Ada, setiap bulan sudah dilakukan penocokan fisik kekayaan dengan catatannya secara manual, selain itu pencocokan juga dilakukan di rapat tahunan yang dilaksanakan oleh BPD, Perbekel, dan Pengawas" (Diah Marlia, 2021).

Pencocokan kekayaan secara fisik dan catatannya dilakukan terlebih dahulu oleh masing-masing unit usaha di BUMDES sehingga jika terjadi kesalahan dapat diperbaiki 
secepat mungkin. Kemudian setiap tahunnya, setiap unit usaha pada BUMDES, BPD, Perbekel dan Pengawas akan bersama-sama melakukan pencocokan terhadap kekayaan BUMDES Tirta Rahayu. (4) Karyawan yang Mutunya Sesuai dengan Tanggung Jawabnya. Proses recruitment karyawan di BUMDES Tirta Rahayu Desa Yeh Sumbul diawali dari masuknya data masyarakat yang mengajukan surat lamaran, kemudian data tersebut diserahkan kepada pengawas dan perbekel Desa Yeh Sumbul untuk mendapat saran dan masukan, selanjutnya masukan tersebut akan dievaluasi bersama oleh pengurus BUMDES Tirta Rahayu dengan persyaratan pendidikan minimal SMA atau sederajat, sedangkan untuk posisi tertentu maka syarat pendidikan minimal sarjana dan merupakan masyarakat asli dari Desa Yeh Sumbul.

"Dalam penerimaan karyawan di BUMDES ini, ketika ada masyarakat yang mengajukan surat lamaran maka data tersebut akan kita setorkan kepada pengawas dan perbekel untuk mendapat pertimbangan dan kemudian akan saya evaluasi bersama pengurus BUMDES, tapi yang terpenting calon karyawan tersebut harus masyarakat Desa Yeh Sumbul, minimal pendidikannya SMA sederajat, dan untuk posisi tertentu harus lulusan sarjana" (Muhlis, 2021).

"Biasanya kalau ada yang mengajukan lamaran kepada ketua BUMDES, kemudian ketua BUMDES akan menyampaikan kepada Perbekel dan pengawas dan akan dibahas bersama pengurus BUMDES" (Diah Marlia, 2021).

Sebelum menjadi karyawan tetap, karyawan di BUMDES Tirta Rahayu akan melaksanakan masa uji coba terlebih dahulu. Selama masa uji coba karyawan tersebut akan belajar melaksanakan pekerjaannya melalui atasannya karena tidak ada pelatihan khusus bagi karyawan tersebut sebelum menjadi karyawan tetap. Selama masa uji coba tersebut karyawan bersangkutan akan membuktikkan bahwa dirinya layak untuk dijadikan karyawan tetap.

"Kalau di BUMDES ini tidak ada latihan khusus seperti karyawan bank dan lembaga yang lain dik, tetapi kalau karyawan baru pasti langsung bekerja sambil belajar disini dengan atasan" (Muhlis, 2021)

"Biasanya karyawan baru akan langsung bekerja disini sambil mereka belajar dalam masa uji coba, kalau untuk pengembangan mutu itu dari atasan ada pelatihan" (Diah Marlia, 2021).

Untuk mengembangkan mutu karyawan di BUMDES Tirta Rahayu Desa Yeh Sumbul biasanya ada pelatihan yang dilakukan dari atasan.

Masalah yang dihadapi BUMDES Tirta Rahayu Desa Yeh Sumbul dalam malaksanakan sistem pengendalian intern pemberian kredit tentu saja akan ada masalahmasalah yang dihadapi baik itu kendala mudah maupun yang sulit untuk diselesaikan. Adapun masalah-masalah yang dihadapi BUMDES Tirta Rahayu Desa Yeh Sumbul didalam sistem pengendalian pemberian kredit yaitu SDM kurang memadai, SDM yang dimiliki BUMDES Tirta Rahayu dirasa masih kurang karna Jumlah karyawan terlalu sedikit dan kualitas pendidikan yang rendah selain itu kedisiplinan pengurus dalam menjalankan tugas dirasa kurang baik, sehingga dalam melaksanakan tugas kerap membutuhkan waktu yang lama, struktur organisasi yang dimiliki BUMDES Tirta Rahayu Desa Yeh Sumbul sudah cukup baik. 
Sistem Pengendalian Intern dalam Pemberian Kredit di Badan Usaha Milik Desa Tirta Rahayu Penerapan Sistem Pengendalian Intern dalam Pemberian Kredit di Badan Usaha Milik Desa Tirta Rahayu :(1) Struktur Organisasi yang memisahkan Tanggung Jawab Fungsional Secara Tegas Sudah diterapkan oleh BUMDES Tirta Rahayu Desa Yeh Sumbul dengan melaksanakan kegiatan operasional sesuai dengan pembagian tugas berdasarkan struktur organisasinya. (2) Sistem Wewenang dan Prosedur Pencatatan yang Memberikan Perlindungan yang Cukup Terhadap Kekayaan Sudah dilaksanakan ini dilakukan dengan setiap transaksi harus diotorisasi dan harus ada tanda tangan Perbekel dan Pengawas untuk setiap transaksi. Ini diketahui berdasarkan informasi yang diberikan oleh narasumber yaitu bapak Muhlis, S.E dan Diah Marlia. (3)Praktik yang Sehat dalam Melaksanakan Tugas dan Fungsi Setiap Unit Organisasi.

Berdasarkan informaasi yang diperoleh dari dua narasumber yang berbeda yaitu dari Bapak Muhlis, S.E dan Diah Marlia keduanya mengatakan bahwa BUMDES Tirta Rahayu telah melaksanakan praktik yang sehat melalui penggunaan formulir yang berbeda pada setiap transaksi, adanya pemeriksaan mendadak, pertanggung jawaban setiap transaksi oleh setiap bidang, dan pencocokan kekayaan. (4) Karyawan yang Mutunya Sesuai dengan Tanggung Jawabnya. Bapak Muhlis S.E dan Diah Marlia yang merupakan sumber informasi dari penelitian ini menyatakan informasi yang sama bahwa BUMDES tirta Rahayu Desa Yeh Sumbul untuk setiap tugas dan fungsi dilaksanakan oleh karyawan yang memiliki mutu sesuai dengan bidang pekerjaannya. Sehingga informasi tersebut dinyatakan benar karena pernyatan yang disampaikan sama oleh kedua sumber informasi. Masalah yang Dihadapi Badan Usaha Milik Desa (BUMDES) Tirta Rahayu dalam Melaksanakan Sistem Pengendalian Intern Pemberian Kredit. Dari hasil evaluasi terhadap unsur-unsur pengendalian intern pada pemberian kredit di BUMDES Tirta Rahayu Desa Yeh Sumbul belum sepenuhnya dilaksanakan secara memadai.

\section{Simpulan dan Saran}

Berdasakan hasil penelitian dan pembahasan di atas, peneliti mendapat kesimpulan berupa Sistem pengendalian intern di BUMDES Tirta Rahayu Desa Yeh Sumbul secara garis besar sudah dilaksanakan sesuai dengan kaidah yang berlaku. Masalah yang dihadapi BUMDES Tirta Rahayu dalam Melaksanakan Sistem Pengendalian Intern Pemberian Kredit adalah SDM yang kurang memadai, SDM yang dimiliki BUMDES Tirta Rahayu dirasa masih kurang karna Jumlah karyawan terlalu sedikit dan kualitas pendidikan yang rendah selain itu kedisiplinan pengurus dalam menjalankan tugas dirasa kurang baik, sehingga dalam melaksanakan tugas kerap membutuhkan waktu yang lama.

Sistem pengendalian intern harus tetap ditingkatkan agar kredit bermasalah dapat berkurang terutama dalam hal kesejahteraan karyawan. Untuk meminimalisir adanya permasalahan dalam pelaksanaan pemberian kredit, sebaiknya perekrutan karyawan harus lebih selektif lagi agar karyawan yang terpilih nantinya memiliki mutu yang sesuai dengan kriteria sehingga nantinya karyawan yang terpilih dapat lebih bertanggung jawab terhadap tugasnya.

\section{Daftar Pustaka}

Amalia, K. D. (2014). peranan badan usaha milik desa (bumdes) sebagai upaya dalam meningkatkan pendapatan asli desa (pades ) serta menumbuhkan perekonomian desa, Journal Of rural and Development. Jurnal Ekonomi, 4(1).

Arikunto. 2001. Prosedur penelitian, suatu pendekatan paktek. Jakarta: Bina Aksaera

Dahlan, Siamat. 2001. Manajemen Lembaga Keuangan "Kebijakan Moneter Dan Perbankan”. Edisi Pertama. Jakarta: Fakultas Ekonomi Universitas Indonesia. 
Ismail. 2014. Akuntansi Bank Teori dan Aplikasi dalam Rupiah Edisi Revisi. Jakarta: Kencana Prenada Media Group.

Kuncoro, Mudrajat dan Suhardjono. 2002. Manajemen Perbankan Teori dan Aplikasi. Edisi Pertama. Yogyakarta: BPFE.

Rivai, Veithzal, dkk. 2004. Credit Manajemen Handbook. Edisi Pertama. Jakarta.

Sastradipoera. 2004. Strategi Manajemen Bisnis Perbankan: Konsep dan Implementasi untuk Bersaing. Bandung: Kappa Sigma.

Sugiyono. 2017. Metode Penelitian Kualitatif. Bandung: Alfabeta.

Sukmadinata, Nana Syaodih. 2011. Metode penelitian pendidikan. Bandung: PT. Remaja Rosdakarya.

Undang-Undang No. 32 tahun 2004 tentang Pemerintahan Daerah. 